\title{
El Ecuador después de Correa (d.C.). Una lectura mesiánica del correísmo
}

\section{Ecuador after Correa (a.C.). A Messianic Interpretation of the Correism}

\author{
Carlos De Domingo Soler ${ }^{1}$ \\ Universidad de Los Hemisferios (Ecuador)
}

ORCID: https://orcid.org/0000-0003-4656-9625

Recibido: 04-03-2020

Aceptado: 13-10-2020

\section{Resumen}

El presente texto plantea la lectura del gobierno de Rafael Correa a partir del concepto de "mesianismo" de Giorgio Agamben, aludiendo a su significación en el contexto de la democracia ecuatoriana y la configuración política de la última década. Partiendo de la teología política y la representación cristológica de la teología de la liberación, estableceremos sucintamente la relación entre ciertos hechos transcurridos durante el correísmo y determinados episodios bíblicos. Para ello, nos serviremos de lo que aquí denomino "juego de identificaciones", permitiéndonos enlazar la narrativa política del correísmo con las narrativas mesiánica y cristiana. Como conclusión, sostengo que el gobierno de Rafael Correa asimiló e incorporó sistemáticamente a su discurso los cánones históricos y axiológicos de la narrativa mesiánica.

Palabras-clave: Correísmo, Ecuador, mesianismo, narrativa, teología política.

\footnotetext{
${ }^{1}$ (c-dedomingos@profesores.uhemisferios.edu.ec) Docente Investigador de la Facultad de Derecho de la Universidad de Los Hemisferios (Quito, Ecuador), y Profesor Titular de las cátedras "Teoría General del Estado" y "Derecho Internacional Público". Algunas publicaciones recientes: "Poder, verticalidad y representación cinematográfica", en Las bellas artes hoy, Tirant lo Blanch, Valencia, 2021; "Breve introducción al neoconstitucionalismo andino para europeos. Posibilidades e imposibilidades", Ius Humani, Law Journal, vol. 9, nº 1, 2020, pp. 9-44; "Juventud, academia y empleo. Análisis de una desconexión", PODIUM, vol. 37, n 1, 2020, pp. 129-146; "Las calles: (des)movilización ciudadana en Quito (2015-2019). Una perspectiva comparada de los movimientos populares de indignación", Democracias, vol. 7, n 2, 2019, pp. 41-67; "Familia, conflicto y violencia en el Ecuador (2014-2019)", Quaderns de Polítiques Familiars, vol. 5, 2019, pp. 41-49.
} 


\begin{abstract}
This article analyzes the Rafael Correa's government based on the concept of "messianism" by Giorgio Agamben, referring to its significance in the context of Ecuadorian democracy and the political set of the last decade. Starting from political theology and the Christological representation of the liberation theology, we will sequentially establish the relationship between some events that took place during Correism with certain biblical episodes. To do this, we will use what I call "identification game", which allows to link the political narrative of Correism with the messianic and Christian narratives. In conclusion, I sustain that the government of Rafael Correa assimilated and systematically incorporated the historical and axiological canons of the messianic narrative into his discourse.
\end{abstract}

Key-words: Correism, Ecuador, Messianism, Narrative, Political Theology.

\title{
1. Introducción
}

Bien es cierto que la figura de lo mesiánico propuesta por Agamben no alude a lo redentor ni a lo salvífico, sino a un futuro potencial en el que la violencia del Estado será erradicada, superando el "campo de concentración" diagnosticado por el filósofo romano. Ahora bien, ¿acaso impide la concreción conceptual del mesianismo agambeniano que este pueda ser empleado para estudiar su incidencia desde una praxis política redentora y salvífica?

A lo largo de la Historia, los pueblos han experimentado el "advenimiento" de una serie de personajes mesiánicos. Con independencia de los colores políticos, la contemporaneidad latinoamericana no es la excepción. Por regla general, los personajes mesiánicos comparten características: surgieron en contextos sociales sumidos en crisis orgánicas y de opresión contra los excluidos, abanderando mensajes rupturistas y soteriológicos propios de la Monarchia Messiae (Agamben 2018: 70). Sin entrar a valorar el fondo político del mensaje mesiánico, la praxis política de los personajes mesiánicos ha ido desligándose de la telología del planteamiento agambeniano, generando ejes discursivos tendentes a lo salvífico y lo redentor, categorías que han terminado constituyéndose como paradigmas de la praxis mesiánica.

En el presente texto trataremos de profundizar en la aplicación práctica y cotidiana de lo mesiánico en la esfera narrativa del correísmo y la Revolución Ciudadana. Para comprobar la existencia de esta conexión nos serviremos del "juego de identificaciones", herramienta que nos permite vincular narrativas preexistentes con discursos políticos ad hoc. El juego de identificaciones es un canalizador de conexiones, un vehículo semántico que concatena referencias 
políticas e ideológicas no-asimiladas con otras referencias religiosas y simbólicas histórica y culturalmente asumidas. Así, el narrador despliega estímulos simbólicos, estableciendo una ligadura de percepción subconsciente entre el discurso político y las distintas reminiscencias culturales, axiológicas e históricas que conforman el imaginario colectivo. No obstante, el juego de identificaciones no marca una equivalencia en sentido postmarxista, sino una "apariencia de equivalencia" o significación metafórica que permite inducir categorías políticas actuales en base a categorías políticas, religiosas, axiológicas e históricas preexistentes. El objeto es constituir en el espacio mental una pluralidad de narrativas como sinonímicas o derivadas, provocando y visibilizando la analogía de los "parecidos de familia" de Wittgenstein (1988: 87).

Con respecto a la narrativa mesiánica, el juego de identificaciones requiere aceptar la presencia hegemónica del cristianismo en la base social del Ecuador -y, en general, de América Latina-, afianzada por el papel predominante de la Iglesia en los ámbitos educativos colonial y poscolonial. En el pensamiento althusseriano, la ideología es un "sistema de representaciones [...], estructuras que se imponen a la vasta mayoría de los hombres, no a través de su conciencia" (Larraín 2008: 125). Es decir, la ideología, como "sistema de representaciones", no es consciente. Precisamente es la idea de las representaciones sistematizadas la que nos permite pensar en la naturalidad con la que los individuos pueden enlazar subconsciente o inconscientemente una pluralidad de elementos discursivos que, apriorísticamente inconexos, son susceptibles de considerarse "conexos por medio del discurso".

\section{Narrativa mesiánica}

El término "versión" alude a la posible coexistencia de una pluralidad de consideraciones discordantes hacia un hecho singular. En sí mismo, apunta intrínsecamente a una pluralidad tal de "versiones" como individuos se refieran al hecho, reconociendo "la posibilidad" de existencias contrapuestas. Como tal, reconoce su no-exclusividad: es una forma, no la forma. En caso de contraposición, incluso admite la posibilidad de una mínima intersubjetividad agónica, favoreciendo la dialéctica argumental.

Por su parte, la "narrativa" no solo nos remite a la estructura literaria "en tres actos" como soporte del discurso, sino a la confección del entorno histórico y axiológico que subyace al relato. La narrativa es absoluta. Funge de dominus dominantium. Desplaza todo punto de fuga pluralista hacia la obligatoriedad ritual de la performatividad. Ahora bien, en Foucault el discurso es constitutivo de sí mismo. Como sugiere Rojas Osorio (1984), "los objetos son formados 
por el discurso mismo" (p. 52). Este, más que literario, es "metaliterario". Al igual que el discurso, la narrativa también se construye en el seno de -y para operar entre- relaciones de poder. Sin embargo, la narrativa no constituye la realidad -no determina el marco ontológico-, sino toda apariencia de realidad -concretando las contingencias ónticas-. La narrativa, como concreción de lo contingente, organiza el conjunto de suturas sociales pertenecientes a lo ilusorio $\mathrm{y}$, con independencia de toda medida de lo real, lo reviste con la apariencia -fáctica, histórica, lógica- de lo posible. Las "versiones" son las mismas contraposiciones democráticas, legítimas en el marco agonista. Por su apertura natural hacia la pluralidad, aceptan la existencia en potencia de "espacios comunes". En cambio, la narrativa rechaza la veracidad y legitimidad de otras narrativas, por cuanto constituyen la negación absoluta de la "única verdad" que se argumenta en su interior, configurando el filtro original de exclusión del Otro. Asistimos al terreno de la obcecación discursiva, de la (de)negación ontológica del Otro ajeno y antitético (Otro $\neg Y o)^{2}$. Según la exterioridad constitutiva de Derrida $^{3}$, el Propio-sujeto y el Otro poseen identidades excluyentes, mismas que "confirman" al primero y "constituyen" al segundo (De Domingo 2019: 42). En sintonía, la subjetivación de Rancière (2004) deja entrever la necesidad del Otro para desclasificar al sujeto in-between. Ahora bien, ¿porqué necesitaría el Propio-sujeto definirse en atención al Otro, si es "Primero"? Decía Eco (1997) que "el hombre, como animal religioso, aspira a elaborar narraciones capaces de proporcionarle una explicación y un modelo, una imagen ejemplar”. Es decir, el ser humano necesita insertarse en una narrativa que justifique su existencia y le sirva de exemplum moral. Por ende, podemos considerar que la religión es "la narrativa" por antonomasia. De ahí que el juego de identificaciones persiga subsumir el conjunto narrativo religioso.

A grandes rasgos, la narrativa mesiánica está conformada por los relatos, dogmas y valores contenidos en las Escrituras, la tradición o el imaginario social, referidos a Jesucristo y a la idea de la "redención" como elemento basilar de la promesa mesiánica. Como "texto universal", la Biblia y sus propuestas morales gozan de trascendencia transcultural. No exento de licencias temporales y consuetudinarias, el contenido moral de las Escrituras sigue siendo aplicable a cualquier contexto, sea a través de su literalidad o de la hermenéutica (Eco 1997: 54). Precisamente, debido a la impronta pedagógica del cristianismo

${ }^{2}$ Esta negación ontológica certifica la ruptura de la ecuación paradigmática de la equivalencia $[\mathrm{a} \Rightarrow$ $\mathrm{b}, \mathrm{b} \Rightarrow \mathrm{c}=\mathrm{a} \leftrightarrow \mathrm{c}]$. Recordemos que ya Saussure mantenía que los términos se constituyen atendiendo primordialmente a sus relaciones diferenciales.

3 Derrida no matizó sobre la bilateralidad del concepto, esto es, si el Yo y el Otro se definen "mutuamente". Según considero, su implementación discursiva es eminentemente unilateral, ya que el Propio-sujeto, por su "condición-primera", no requiere del Otro para autodenominarse: "Yo soy $Y o$ "; lo cual no ocurre a la inversa: "el Otro es Otro porque Yo lo declaro Otro". El Otro es construido, una nominación exógena: "Yo te designo Otro $\Leftrightarrow$ tú eres Otro"; mientras que el Propio-sujeto se auto-adjudica sus cualidades identificativas: "Yo me designo $\mathrm{X} \Leftrightarrow$ Yo soy X". Cfr. Agamben 2010: 60. 
en la enseñanza occidental, a la evangelización de los sectores subalternos latinoamericanos y a la sobreexposición religiosa en la cotidianeidad social, la narrativa cristiana es transversalmente asumida como canon axiológico. Tampoco podemos ignorar que del cristianismo descienden las bases de la cultura occidental. Según Rousseau (2011), “jamás fue fundado un Estado sin que la religión le sirviese de base" (p. 141), ya que "desde el origen de las naciones, la religión sirve de instrumento a la política” (p. 53), evidenciándose la trascendencia del fenómeno religioso en la articulación identitaria y política de los pueblos. La importancia histórica y política de las Escrituras como eje axiológico es impostergable. Siguiendo a Dickinson (2015), "the Bible was the great form for the articulation of the religious, moral and political protests against the power" (p. 124).

Al igual que el fenómeno religioso, las narrativas políticas invocan una intersubjetividad unificadora a su alrededor, articulando creencias compartidas sobre las que fundar una "comunión narrativa" similar a la koinonía, tornándose el discurso particular de los agentes políticos en dogma de fe. Es así como se constituyen nexos imaginarios-simbólicos entre las narrativas políticas y mesiánica. No se trata de generar nuevas realidades, sino de dotar de nuevos sentidos a las realidades preexistentes, apropiándose del sustento pedagógico de los relatos y símbolos cristianos, culturalmente incorporados a nuestro vocabulario comunitario. Sirviéndose de la comunicación, la propaganda y su incidencia mediática, los agentes políticos actúan como "Narradores", desplegando un conjunto de estímulos narrativos-mesiánicos. Gracias al juego de identificaciones, los agentes políticos construyen y/o prosiguen narrativas, generando discursos, imágenes y productos inconscientemente reconocibles a razón del texto mesiánico, anexionándose la completitud axiológica que la narrativa mesiánica evoca en el imaginario colectivo. Sin embargo, debe darse cierta compatibilidad narrativa - una adecuación a los principios de semejanza y experiencia de la Gestalt, por ejemplo-, como ejemplifica el vigente influjo sociocultural del cristianismo en América Latina, junto con la omnipresencia globalizada de los sitios comunes de la cultura pop ${ }^{4}$.

Preexistiendo una base religiosa en un espacio social determinado -el Ecuador-, más plausible será que germine el juego de identificaciones tras estimularlo mediante patrones de similitud y compatibilidad. Más aún si "lo previo" es articulado como "tradición". De acuerdo con Geertz (2003), podemos considerar la religión como un "sistema de símbolos que genera

\footnotetext{
4 En comunicación política observamos los efectos Rocky Balboa y David vs. Goliat, la implementación política de las tramas maestras, la "transformación del héroe" aristotélica, los patrones psicoanalíticos del héroe del monomito de Campbell (1972) -la llamada de la aventura y el despertar del yo-y su valoración moral preponderante. "The Lord of the Rings" y "Game of Thrones" son ejemplos paradigmáticos de la adversidad del contexto histórico, el antagonismo, la misión y la posibilidad apocalíptica.
}

Araucaria. Revista Iberoamericana de Filosofía, Política, Humanidades y Relaciones Internacionales, año $23, \mathrm{n}^{\circ} 46$. Primer cuatrimestre de 2021. Pp. 195-214. ISSN 1575-6823 e-ISSN 2340-2199 https://dx.doi.org/10.12795/araucaria.2021.i46.10 
ánimos y motivaciones poderosas, persuasivas y persistentes en los seres humanos" (p. 93). Es evidente, reconociendo su mayoritaria religiosidad, que la sociedad ecuatoriana conoce el sistema axiológico cristiano y el conjunto de relatos que lo fundamentan y promueven, ya que la "comunicación de Dios" -la Revelación- está naturalmente inserta en "una cierta historia" (Martini 1997: 69) ${ }^{5}$. Dicho conocimiento no requiere, siquiera, de la fe: basta con que el pensamiento místico colectivo muestre cierta apertura hacia la espiritualidad cristiana. Como es sabido, Gramsci (2009) asimiló religión e ideología, tildando a la primera como un elemento narcotizador influyente en la construcción social de las normas conductuales. En palabras de Larraín (2008), "en la medida que la religión es una fuente de orientaciones prácticas para la acción, además de ser una visión del mundo, es para Gramsci un nivel clave en que se vive la ideología" (p. 114). En tal caso, si "la religión es una ideología", habida cuenta que ambas proponen y exigen una praxis litúrgica, performativa y ritual, ¿cabe afirmar análogamente que "la ideología es una religión”? ¿E, incluso, que guardan más convergencias que divergencias?

\section{El tiempo del mesías. El personaje cristológico según la teología de la liberación}

Según la narrativa de la Revolución Ciudadana, antes de la irrupción de Correa el Ecuador afrontaba la denominada "larga y triste noche neoliberal" (Correa 2009). El Ecuador "antes de Correa" era, pues, un país en crisis orgánica $^{6}$, sumido en la imposibilidad del pleno ser-existir. ¿Y cuándo, sino durante las crisis orgánicas, necesitan las comunidades políticas el advenimiento mesiánico?

Acorde al relato, existe una brecha epocal entre los tiempos "antes de Correa" y "después de Correa". El Ecuador a.C. nos recuerda las injusticias y los atropellos padecidos por el pueblo a manos de la "partidocracia", la "banca corrupta" y los organismos internacionales. En esta época dominada por "lo terrible", la promesa mesiánica del correísmo ofrecía la potencial extinción de la hegemonía neoliberal. En contraposición, el Ecuador d.C. trajo consigo el mayor progreso socioeconómico e institucional de la historia nacional (léase Marcos 6:30-34). La venida mesiánica de "Rafael Correa" causó una dislocación temporal, fraccionando el continuo y marcando el principal acontecimiento histórico desde el fin del colonialismo. "Queridos ecuatorianos y ecuatorianas: llegó la hora. No hay que tener miedo", dijo Correa en su discurso de posesión en enero de 2007. Según Agamben (2011), la tarea original de las revoluciones

\footnotetext{
${ }^{5}$ Véase Spinoza 2014: 94. Cfr. Benedicto XVI 2007: 7-9.

${ }^{6}$ Véase Gramsci 2001: II, 37, y 2003: 62.
} 
es "cambiar el tiempo" (p. 129). A la hora de establecer un contexto mesiánico el "tiempo" no es casual, ya que su ruptura -"antes de" y "después de"- es el paso primigenio hacia la utopía mesiánica ${ }^{7}$. Frente a la esterilidad de las pulsiones reformistas, la revolución es el sujeto histórico de la utopía. ¿Acaso no son las revoluciones los acontecimientos mesiánicos modernos?

"Rafael Correa" era destinatario de una misión weberiana: crear una escisión temporal entre "lo previo-lo terrible" y la plenitud de un futuro de revolución y esperanza social ${ }^{8}$. El advenimiento correísta generó un breakpoint en la forma de performar la política. La distinción "a.C." y "d.C." marca nítidamente la separación entre una etapa histórica oscura y en metástasis social -en la que "todos íbamos errantes como ovejas" (Isaías 53: 6)-, y el logro de la refundación nacional. Reinstaurando la Gesamtheit del Ecuador, Correa se constituyó como el idóneo configurador de la identidad nacional, en cuya unidad se genera la pertenencia al Volkgeist. Como construcción narrativa, "Rafael Correa" es el "Pueblo hecho carne", el paradigma de soberano capaz de decidir sobre la excepción y "lo excepcional" (Agamben 2019), elevando a norma jurídica y moral su voluntad y desplegando una fuerza afectiva capaz de originar una forma colectiva de identificación, confundiéndose simbióticamente "lo libidinoso del pueblo" y "lo libidinoso de Rafael Correa" (De Domingo 2019) ${ }^{9}$. Él representa el jouissance social, erigiéndose como el elemento decisor de lo nacional. Consecuentemente, sus adeptos son la "sal de la tierra" (Mateo 5: 6, 11), persiguiendo el placer escatológico de "ser Uno en Él". Correa es un "sumo sacerdote", una figura espiritual investida de poder pastoral (Foucault 1988: 4). Lejos de denostar la "moral de rebaño", "Rafael Correa" la sutura, legitimando en la aclamación popular su voluntad de poder (Nietzsche 2011). Si "lo salvífico" pertenece al correísmo (Juan 3: 16), fuera de él solo cabe condenación (Juan 3: 18; Marcos 16: 16), ya que la única vía de acceso al "logro último de la Revolución" pasa por declarar públicamente la cualidad mesiánica de Correa (Romanos 10: 9-10), no bastando con la "simple creencia" (1 Crónicas 16: 24; Mateo 7: 16; Eclesiastés 9: 10; 2 Corintios 5: 10; Tito 3: 1; Santiago 1: 22, 2: 14, 3: 13).

Como reinterpretación contextualizada, el personaje "Rafael Correa" no fue la asimilación narrativa de un Cristo genérico -según lo católico, apostólico, romano y occidental-, sino de la revisión cristológica de la teología de la liberación. Se trata, decía Sorel, de un "Cristo revolucionario" (Gramsci 2005: 105). Podemos escuchar esta visión cristológica en el grupo Ska-P (1998):

\footnotetext{
${ }^{7}$ No olvidemos que Bloch basó su patrimonio teórico en la Biblia y la historia del cristianismo (Löwy 2015: 354). Sobre la utopía latinoamericana, véase Aínsa 1990.

${ }^{8}$ Cfr. Žižek y Gunjević 2013: 7-11.

${ }^{9}$ Con motivo de los primeros reclamos judiciales contra Correa, trascendió en 2018 el hashtag \#SiEsConCorreaEsConmigo, deslizando la tautología [Rafael Correa T Ecuador $\leftrightarrow$ Pueblo], misma que en 2020 perdura tras la sentencia condenatoria del denominado caso "Sobornos 2012-2016".
} 
Jesucristo era un tío normal, pacifista, intelectual,

Siempre al lado de los pobres defendiendo sus valores,

Siempre en contra del capital,

Crucificado como un animal, defendiendo un ideal ${ }^{10}$.

Según sostuvo María López Vigil, "Jesús es anarquista y socialista" (Marroquín 2017), consideración cristológica revolucionaria presente en las series radiofónicas "Un tal Jesús" (1981) y "Otro Dios es posible" (2008) de los hermanos López Vigil ${ }^{11}$. En la misma línea, se preguntaba el actual candidato presidencial Yaku Pérez Guartambel (2008): “ ¿Fue Cristo un socialista? El evangelio nos trae pasajes auténticamente socialistas o comunistas" (p. 40). La teología de la liberación posee un marcado influjo gramsciano, repensando "lo cristiano" desde sus características primitivas, mimetizando el mensaje de la salvación con las inquietudes de la clase subalterna ${ }^{12}$ y cuestionando la autoridad moral de los jerarcas católicos (Dickinson 2015: 125). La idea de la salvación "por el único poder de la Palabra”, independiente de las normas de la Iglesia Católica ${ }^{13}$, contribuyó a que la teología de la liberación ganara la pugna hegemónica por la educación popular latinoamericana ${ }^{14}$, haciendo músculo político gracias a la "fraternidad entre revolucionarios cristianos y revolucionarios ateos o agnósticos" (Löwy 2019: 8). Esta lectura es, sostiene Dickinson (2015), propiciada por la propia literalidad bíblica: "The Bible was the weapon of poverty and insurrection; it was the world that made men rise up against the law and against glory, against the unjust law of kings and beautiful glory of the Church" (p. 125)

\section{Praxis del juego de identificaciones: episodios mesiánicos}

En este epígrafe contrastaremos determinados episodios surgidos durante el correísmo con respecto a la narrativa mesiánica ${ }^{16}$. Para ello, introduciré las

\footnotetext{
${ }^{10}$ Ska-P (1998). Villancico. En Eurosis. Alacrán Producciones.

11 Véase López Vigil 2015.

12 Véase “inculturación de la evangelización” en Scannone 1990: 179.

13 Al contrario, Berdiáiev (2019: 41), localiza en la Iglesia el escalafón fundamental del proceso de la divino-humanidad.

${ }^{14}$ Cfr. Proaño 1987. Para una perspectiva histórica latinoamericana, acúdase a Löwy 1999. Sobre la relación entre Gramsci, teología y América Latina, véase Cuda 2016: § Recategorizaciones éticas y politicas.

${ }^{15}$ Ratzinger (2011: 15) matizó que "el poder de Jesús reside en la pobreza”, resaltando la presencia en "el alma de los pueblos latinoamericanos [...] [del] Dios cercano a los pobres" (Benedicto XVI 2007: 9). Sobre la relación entre pobreza y cristianismo, véase Mateo 8: 20 y Filipenses 2: 7.

${ }^{16}$ Con respecto a la "Pasión de Rafael Correa", episodio arquetípicamente mesiánico transcurrido el 30 de septiembre de 2010 - conocido como 30S, expresión que un par de años después fue patentada y registrada por la Presidencia de la República-, véase De la Torre 2015: 181. Cfr. Pérez Ordóñez 
identificaciones a analizar mediante breves construcciones gramaticales, con el objetivo de guiar y delimitar las equivalencias entre lo fáctico y lo mesiánico ${ }^{17}$.

Así como Jesucristo expulsó a los mercaderes del Templo, Rafael Correa expulsó a los mercaderes de la Patria.

Durante su presidencia, Correa confrontó a las denominadas “élites neoliberales", señalándolas como los entes antagónicos del pueblo ecuatoriano. Expulsando del Ecuador a los organismos financieros internacionales, proyectó una imagen de determinación y energía contra la quimera neoliberal ${ }^{18}$. Levantándose contra las instituciones supranacionales, Correa deslizó un juego de identificaciones con el Jesucristo enérgico y temperamental descrito en el episodio de la expulsión de los mercaderes ${ }^{19}$. Leyendo este episodio en clave moderna, los mercaderes habían profanado un espacio sagrado con sus acciones capitalistas, convirtiendo "la casa de Dios en una cueva de ladrones" (Isaías 56: 7; Jeremías 7: 11), y consecuentemente, Jesucristo expulsó a quienes deshonraron el Templo (Juan 2: 14) ${ }^{20}$. Expulsando a los mercaderes, Jesucristo restituyó la sacralidad del "espacio dedicado a Dios". Del mismo modo, tras su primera victoria electoral, Correa aseguró haber "recuperado la patria" (TeleSUR 2006), restituyendo así la sacralidad del suelo nacional con el destierro de quienes lo habían violentado y expoliado. Como él mismo proclamó en su discurso de posesión, "hoy, la Patria ya es de todos" (Correa, 2007).

Así como Jesucristo enseñó a los excluidos, Rafael Correa enseñó a los excluidos.

Los Enlaces Ciudadanos del correísmo resultaron atractivos para determinados segmentos ciudadanos debido a su valor pedagógico (Cerbino,

2010.

${ }^{17}$ En aras de evitar confusiones al lector, debo matizar que en modo alguno las construcciones a las que me refiero representan mi propio posicionamiento ideológico o una hipotética defensa política sobre la problemática estudiada en este texto.

18 Así sostuvo Correa en su discurso de toma de posesión de 2007: "El momento histórico de la Patria y de todo el continente, [...], una vez superado el dogma neoliberal y las democracias de plastilina que sometieron personas, vidas y sociedades a las entelequias del mercado".

${ }^{19}$ Resultando firme y enérgico por causa de "su amor hacia su pueblo", Correa conjugó la proclama nietzscheana: "un César romano con el alma de Cristo" (Nietzsche 2018: §976); máxima que explica Desmond (2015): "We might take the Roman Caesar as the epitome of political sovereignty and the soul of Christ as the solicitation and witness of agapeic service" (p. 98). También Correa (2007) sugirió una máxima similar: "[...] que el Señor me dé un corazón grande para amar, pero también fuerte para luchar".

${ }^{20}$ Existe correspondencia entre la crítica al capitalismo hecha por Benedicto XVI (2007: 16) y la relación que establece el Documento de Aparecida entre la santidad y la acción contra "la realidad urgente de los grandes problemas económicos, sociales y políticos de América Latina" (Consejo Episcopal Latinoamericano 2007: §148).

Araucaria. Revista Iberoamericana de Filosofia, Política, Humanidades y Relaciones Internacionales, año $23, \mathrm{n}^{\circ} 46$. Primer cuatrimestre de 2021. Pp. 195-214. ISSN 1575-6823 e-ISSN 2340-2199 https://dx.doi.org/10.12795/araucaria.2021.i46.10 
Maluf y Ramos 2016: 43) ${ }^{21}$. Este formato audiovisual permitió a Correa explicar con sencillez gran variedad de cuestiones consideradas por la población como complejas, técnicas o académicas. Mientras la clase política del "Ecuador a.C.", conformada por falsos profetas (Mateo 7: 15), impidió el acceso a la educación de la clase subalterna (Juan 7: 47), Correa la empoderó con "conocimiento y consciencia de sí misma" (Efesios 3: 19). Si nos remontamos a la infancia de Jesucristo y a los tres años de vida pública, observamos que desarrolló una gran labor pedagógica (Mateo 13: 10; Marcos 4: 10; Lucas 2: 40, y 8: 9). Mediante las parábolas, Jesucristo expuso nociones complejas con la cercanía de un lenguaje metafórico e inclusivo.

Así como Jesucristo empoderó a los excluidos de la sociedad, Rafael Correa empoderó a los excluidos por el neoliberalismo.

Según la narrativa correísta, el Ecuador enfrentó durante la "larga y triste noche neoliberal" (Correa 2009) un periodo de galopante inequidad y desigualdad social (Correa 2007: III). Este es el contexto adverso-apocalíptico que, según las pautas dramáticas aristotélicas, justifica la irrupción del héroe. Desde sus inicios en política, Correa asumió el papel de héroe artúrico de los “de abajo", enfrentando la opresión neoliberal y guiando a las clases subalternas al edén de la Revolución Ciudadana. La esperanza social sería y sigue siendo, pues, persistente en el discurso correísta. Desde el discurso de toma de posesión, en el que declaró: "Aquel que caminó sobre la mar y calmó tempestades, también nos ayudará a superar estos difíciles pero esperanzadores momentos" (Correa 2007); hasta el autodenominado \#ElBinomioDeLaEsperanza -conformado por la pareja de candidatos presidenciales del correísmo para las Elecciones Presidenciales de 2021- y la plataforma "Unión por la Esperanza" (UNES), la noción "esperanza" está más que presente.

Jesucristo, supuesto "personaje revolucionario", no solo criticó la exclusión social, sino que se acercó a los leprosos -paradigma antonomástico de la marginación-y compartió con ellos (Mateo 8: 1; Lucas 5: 12; Marcos 1: 40). Son constantes las referencias bíblicas a la ternura con la que Jesucristo abrazaba a los socialmente considerados "abyectos" (Números 5: 1). Como figura en el texto de la III Conferencia General del Episcopado Latinoamericano (1979), "Cristo está al lado de los pobres", afirmación que se corresponde con la predilección natural que, según Marcos 12: 41, y 25: 42, sentía Jesucristo por los pobres.

Así como los niños de Jerusalén se acercaron y abrazaron a Jesucristo, los niños del Ecuador se acercaron y abrazaron a Rafael.

${ }^{21}$ Mi criterio personal es que, en contraposición, cada vez que Correa sostenía un micrófono solemnizaba una declaración de hostis contra el "enemigo interior" (Schmitt 2016: 76).

Araucaria. Revista Iberoamericana de Filosofia, Política, Humanidades y Relaciones Internacionales, año $23, \mathrm{n}^{\circ} 46$. Primer cuatrimestre de 2021. Pp. 195-214. ISSN 1575-6823 e-ISSN 2340-2199 https://dx.doi.org/10.12795/araucaria.2021.i46.10 
Relata Marcos 10: 13 que, cuando los discípulos impidieron a los niños acercarse a Jesucristo, este "se indignó y les dijo: dejad que los niños vengan a mí". Por consiguiente, ver a Jesucristo rodeado de niños es un recurso característico de la imaginería contemporánea, reforzando la noción catequética de vocación de servicio. La mayoría de los regímenes totalitarios han insertado sistemáticamente a la infancia en sus contenidos propagandísticos, persiguiendo lo que en comunicación política suele denominarse "transferencia de valor" 22 . La infancia es el símbolo de la perdurabilidad comunitaria. Defendiendo la infancia, el Líder defiende la "inocencia del Pueblo" y la posibilidad de la continuidad. Generalmente, la niñez representa al pueblo vulnerable, que requiere desesperadamente del progenitor para sobrevivir, tal y como sostiene el marco del "padre estricto" de Lakoff (2016). Sin embargo, mientras el Líder es severo con los adultos, "culpables" de sus faltas y no-inocentes, es bondadoso y paciente con la infancia. En palabras de Correa, "mi sueño, desde la humildad de mi Patria morena, es ver un país sin miseria, sin niños en la calle" (2007). El Líder, inspirado en el agapeic God y el agapeic servant propuesto por Desmond (2015), "ama" como solo la divinidad puede hacerlo (1 Juan 3: 1, y 4: 10; Romanos 5: 8; Salmos 36: 7). Así solicitó el propio Correa a la ciudadanía: "Pidan por mí para que el Señor me dé un corazón grande para amar" (2007). De esta manera surge el "efecto espejo", mediante el cual las conductas del Líder son moralmente aprobadas por los sujetos, identificándose con él por cuanto comparten las conductas que estos mantienen con su propia progenie $^{23}$.

Así como Jesucristo perdonó a quienes le crucificaron, Lenín perdonó a quienes atentaron contra su vida.

Describe el Nuevo Testamento que Jesucristo "amó incondicionalmente" (Mateo 5: 43; Juan 19: 25). Presentado como "candidato del amor", Moreno ${ }^{24}$ buscó identificarse con el ejemplo sobrenatural del amor de Cristo (Mateo 25: 42; Juan 13: 34). Sabiendo que la psicología de los personajes se articula según el contexto dado, Moreno se configuró en las Elecciones de 2017 como "líder

${ }^{22}$ En el Ecuador ha sido frecuente el empleo propagandístico de imágenes de infantes alrededor de los personajes políticos. Obsérvese la publicidad del colectivo "Rafael Contigo Siempre", el afiche de la misión "Toda una vida" de Lenín Moreno y sus spots de campaña, y el spot presidencial de Jaime Nebot de 1996. En la antesala de las Elecciones Presidenciales de 2021, ya comienzan a observarse réplicas por enésima vez.

${ }^{23}$ Ironizaba el cómico estadounidense George Carlin que los políticos suelen esconderse detrás de la bandera, la Biblia y los niños. Siendo la bandera el símbolo de unidad nacional y la Biblia la representación del sistema de valores dominantes, la infancia sintetiza "el futuro amable de la comunidad".

${ }^{24}$ Nótese que, si bien en la actualidad constituyen identidades partidarias antagónicas, Moreno representó la opción electoral del correísmo ante la incapacidad legal de Rafael Correa para postularse a la reelección en 2017 . 
conciliador", distanciándose de la personalidad de Correa y la fricción popular heredada de las postrimerías del correísmo. Tras la experiencia correísta, la ciudadanía demandaba un pacificador capaz de gestionar la discordia ${ }^{25}$, cercano al "líder-siervo" descrito en Juan 13: 1 y Mateo 23: 11. Desde su investidura, Moreno enfrentó el desafío de gobernar un país conflictuado. Con objeto de superar un eventual bloqueo, el nuevo régimen activó una estrategia de desarticulación/rearticulación discursiva. En lugar de la agresión mediática y la polarización, Moreno reclamó conciliación y el perdón de unos a otros. Precisamente, es el perdón la noción definitoria de la moral cristiana. Frente a la retribución taliónica (Éxodo 21: 23; Deuteronomio 19: 21; Levíticos 24: 7), Jesucristo introdujo la misericordia y el perdón (Lucas 6: 35, 7: 47, 23: 34; 1 Juan 1: 9, 2: 1; 2 Pedro 3: 9; Efesios 1: 7, 2: 8; Colosenses 1: 13). En consonancia, Moreno alentó “el perdón” como foco discursivo ${ }^{26}$.

"Así como los primeros cristianos sufrieron el martirio por defender su fe, los líderes latinoamericanos procesados sufrieron lawfare por defender al pueblo".

Durante los últimos años distintos líderes políticos han sido procesados judicialmente ${ }^{27}$. Lejos de perder sus "halos de santidad"-credibilidad, prestigio, simpatizantes-, han trascendido como mártires políticos. Etimológicamente, "mártir" procede de martyros, "testigo" en griego. Tras la introducción del cristianismo en Roma, el término empezó a describir a aquellos que enfrentaban la muerte en calidad de "testigos de la luz de Cristo" (Hebreos 11: 37; Juan 1: 6; Mateo 10: 28, 16:24, 24: 9; Lucas 11: 50; Hechos 7: 58, 21: 13, Apocalipsis 2: 3, 7: 14). Por analogía, bien podemos entender "mártir" como "testigo de la causa". Al igual que los santos mártires, los personajes "martirizados" representan un baluarte ideológico, visible y graficado, colectivamente identificados como héroes, toda vez que el paradigma cristiano de héroe se corresponde con el mártir (Strauss y Cropsey 1993: 190). El personaje martirizado se introduce en

${ }_{25}$ En palabras de Moreno (2017), “seguimos empeñados en reconciliar al país; para el odio, no cuenten conmigo".

${ }^{26}$ En uno de los spots electorales de Alianza PAIS, Moreno relataba cómo perdonó a los agresores que le habían postrado en silla de ruedas, mientras que su progenitor recordaba que, aún convaleciente, su hijo le dijo: "yo ya les perdoné” (Cfr. Salmos 86: 5 e Isaías 53: 12). Acto seguido, Moreno pontificaba: "el gran sanador es el perdón, yo volví a recuperar la felicidad cuando empecé a rezar por los chicos que me dispararon” (Vamos Lenín 2017).

27 No es el objeto del presente texto discernir si tales procesamientos se encuentran sujetos a Derecho o al denominado lawfare, noción que sienta cierto juego de identificaciones con las persecuciones que sufrieron los cristianos primitivos por defender la Palabra (Cfr. Proverbios 10: 11, 29: 7; Salmos 1: 5; Job 36: 7; Romanos 1: 17; Mateo 27: 19). Recientemente está surgiendo literatura sobre el denominado caso "Sobornos 2012-2016", por el cual Rafael Correa y distintos barones del régimen recibieron sentencias condenatorias. En la esfera personal, debo reconocer que estoy lejos de simpatizar con el correísmo. Sin embargo, se percibe que, tras la acusación de Correa contra la Fiscalía General del Estado en febrero de 2020 ante la Comisión Interamericana de Derechos Humanos por presunto fraude procesal, el discurso correísta comienza a acercarse a los relatos del martirologio.

Araucaria. Revista Iberoamericana de Filosofia, Politica, Humanidades y Relaciones Internacionales, año $23, \mathrm{n}^{\circ} 46$. Primer cuatrimestre de 2021. Pp. 195-214. ISSN 1575-6823 e-ISSN 2340-2199 https://dx.doi.org/10.12795/araucaria.2021.i46.10 
la narrativa como un nuevo sujeto de culto -por ejemplo, Jan Palach, Guevara, Allende, Puig Antich, Chávez, etc.--, un símbolo de rápida significación, y un novedoso producto de marketing e imaginería. En el seno narrativo, el mártir se constituye en speculum principium, en un modelo histórico de conducta en cuyo reflejo sus correligionarios encuentran aprobación o reprobación, inspirador de una especial fortaleza ideológica y fecunda réplica. Como se le atribuye a Tertuliano, "sangre de mártires, semilla de cristianos" (Miralles 2004).

\section{5. "Lo que está por venir". Elegidos y no-elegidos}

Por cuanto "todos somos pecadores", la necesidad de redención es transversal. De ahí el deslizamiento mesiánico en sociedades sumidas en crisis orgánicas. De nuevo, ¿cuándo, sino durante la mayor de sus crisis, podría una sociedad clamar por el advenimiento mesiánico y su componente de purificación? La aparición correísta, más que un "cambio" agambeniano, supuso una "metamorfosis" en el sentido de Beck (2017: 17-35).

"Lo que está por venir", esencia de la promesa mesiánica, no se certifica con la consumación definitiva de una revolución estática, sino de una acción progresiva y en movimiento. La revolución "no se agota", ya que "acaba de comenzar". Según Agamben, todo progreso palpable "ahora" solo es un paso más en el itinerario de "lo que está por venir". Precisamente es la noconsumación revolucionaria lo que legitima su atemporalidad y obligada subsistencia, su medida superior a la dimensión del propio tiempo. Por cuanto la misión revolucionaria se auto-percibe "colosal", su cumplimiento es inexigible en la inmediatez, únicamente a través de su propio rodaje. En palabras de Gramsci (2005), la revolución "no se instaura en fecha fija, sino que es un cambio continuo, un desarrollo infinito" (p. 44). Las revoluciones se legitiman en los planos narrativo y teleológico como sempiternas superestructuras en continua construcción. Sobre esta idea, Jardón (2014) matiza que en las revoluciones modernas "el resultado directo no [es] el socialismo, sino la garantía de evolución hacia él, es un desarrollo, un cambio continuo" (p. 38). Idealmente, el agotamiento del proyecto revolucionario "consumado", surgiría con la eventual constatación fenomenológica de la "metamorfosis". Hasta "entonces" la revolución debe permanecer vigente, ad ceternum. En el Ecuador se vislumbra fácilmente esta lógica en uno de los eslóganes oficiales más repetidos: "La Revolución Ciudadana está en marcha". Según el discurso, la Revolución Ciudadana se encontraba "en constante y perpetuo movimiento", movilizándose inexorablemente hacia el futuro. 
Como dijimos, su indefinición temporal hace inexigible la inmediatez edénica $^{28}$. Si bien no podemos precisar "cuándo", tenemos la certeza de que tendrá lugar "irremisiblemente" (Lucas 9: 11; Deuteronomio 7: 9; Apocalipsis 21: 1) $)^{29}$, ya que "marcha hacia su cumplimiento, y no dejará de cumplirse" (Habacuc 2: 3). Como "lo sacro" supera las leyes terrenales, también la cadencia revolucionaria supera el ritmo convencional. Efectivamente, "nada choca más con la idea del progreso que la posibilidad de que la meta ideal pueda y deba, acaso, realizarse en este instante" (Tiedemann, en Kuffer 2011: 133). La concepción humana del tiempo es histórica y lineal, habida cuenta que desde el "comienzo" nos dirigimos sin dilación hacia el "final" (Châtelet 1982: 192) en "un continuo morir" (Lacalle 2006: 92). La historia, afirmaba San Agustín, es una trayectoria rectilínea iniciada en el Génesis y destinada a concluir en el Apocalipsis $^{30}$. Por cuanto es una "criatura Suya" (Isler 2008: 195), el tiempo es una cuestión menor para Dios (Salmos 39: 4, 90: 2, 113), ya que "Dios no tiene tiempo" (Isler 2008: 198; Apocalipsis 1: 8). Y al igual que la narrativa mesiánica, la narrativa revolucionaria plantea la promesa de la parusía, evento mesiánico desligado del tiempo (Eco 1997: 19; Cuda 2016: 134).

El pensamiento cristiano no plantea mayor goce que entrar al Reino de los Cielos y participar de la presencia de Dios $^{31}$. Este es un estado irreversible, si bien también es un estado postergado y aplazado, condicionado por nuestras acciones (Juan 11: 40; Apocalipsis 2: 2). Por ende, alcanzar la vida zoé deriva de la validación ex post de una serie de conductas realizadas ex ante (Juan 12: 47; Apocalipsis 21:27, y 22: 12). Por analogía, ¿cómo pueden los sujetos, según las narrativas políticas, optar a la vida zoé? A través de la comunión narrativa. La koinonía entre individuos y agente mesiánico se certifica con la comunión, con la participación narrativa sintomática de lealtad y sumisión (Mateo 16: 24; Juan 15: 4). Solo así el individuo aspira al goce escatológico de la pertenencia política-mesiánica: "ser Uno en Él"32. Para ello, quien "cree" debe performar su creencia, difundir y predicar el evangelio (Mateo 18: 20; Lucas 5: 10; 1 Juan 4: 15; Marcos 16: 15; Apocalipsis 22: 10), ya que ignorar el mandato de difundir la buena nueva (Mateo 22: 37) entraña "tibieza"33. Como sugiere Foa (1997), "el creyente que sabe lo que es verdad y lo que

${ }^{28}$ Cfr. Juan 2: 4 y Eclesiastés 3: 1.

29 Cuda (2016), partiendo de Scannone, es quien considero que con mayor sencillez define el momento soteriológico: "ya pero todavía no" (p. 135).

${ }^{30}$ Cfr. Agamben 2019: 134.

31 Ramos (2008) asegura que "los hombres están ordenados a la comunión perfecta de vida con Dios, fin último de toda la sociedad humana”. Salvando las distancias, podemos asimilar esta idea con la fruitio beatifica de Spinoza (2014).

32 Siguiendo a Agamben (2018), podríamos asimilar este ser-Uno-en-Él con el "body politic que se forma por el pueblo de los súbditos que no poseen un cuerpo propio, sino que existen puntualmente solo en el cuerpo del soberano" (p. 71).

${ }^{33}$ En los contextos dicotómicos, el amitié impartiale es la excepción. Entre el "frío" y el "calor" no se admite la "tibieza", "estado nauseabundo para Dios" (Apocalipsis 3: 16). Cfr. Agamben 2018: 26. 
es justo tiene no solo el derecho, sino el deber, de lograr que los demás se adecuen a la verdad y la justicia" (p. 131) 34 $^{34}$ Lo sagrado, según el correísmo, se adecúa en lo terreno, ya que "el Reino de Dios debe ser construido aquí, en la tierra" (Correa 2007).

En el imaginario cristiano, "lo que está por venir" se encuentra descrito en la trama apocalíptica (Apocalipsis 1: 1-3). Para Martini (1997), lo apocalíptico es la "constatación de una gran de reserva de esperanza como resistencia a la desolada resignación de un tiempo presente de sufrimiento, desazón y opresión, al cual la segunda venida mesiánica pondrá fin, trayendo consigo un futuro utópico" (p. 23). Entendiendo que la teorética del apocalipsis no se limita a la catástrofe, el autor equipara "lo apocalíptico" con "lo esperanzador"35. El apocalipsis, en cambio, brinda un punto de fuga narrativo, una visión amable que confirma la erradicación definitiva de las penurias del tiempo presente ${ }^{36}$. Por lo tanto, el clímax escatológico del Armagedón -más palmario en el Ragnarök- no es tanto la destrucción sino el resurgimiento de construcciones sociales armónicas con lo divino.

Gramsci enseñaba que el ansia revolucionaria -la potencialidad de la revolución- subyace a la cotidianeidad hegemónica, en referencia a una revolución latente, en hibernación, según la metáfora marxista del viejo topo. Mientras la efectividad de las conquistas violentas es volátil -encuentran resistencias y tensiones contestatarias-, la alternativa a la subsistencia coactiva es la hegemonía. En Gramsci, más que de "hegemonía”, deberíamos hablar de "ciclos hegemónicos" - la fricción constante entre hegemonía y contrahegemonía-, ya que "todo grupo dominante espera hasta agotar su función, aguardando su desintegración” (Gramsci 2005: 488). Antes, así lo contempló el pensamiento soreliano: "a una forma de sociedad no se opone tan solo otra, distinta y positiva destinada a reemplazarla, sino también su desintegración y decadencia" (Laclau y Mouffe 2015: 69). El reto de toda hegemonía es, pues, no caer en espiral hacia su propia desaparición. Lo fundamental no es la conquista en sí misma, sino su conservación temporal. En este sentido podemos considerar el ejemplo paradigmático del cristianismo. El cristianismo se difundió pacíficamente durante sus cuatro primeros siglos penetrando en las conciencias. Y de Labriola (1973) aprendimos que "no hay hecho histórico que no esté precedido, acompañado y seguido por determinadas formas de conciencia" (p. 131). Desde su irrupción, el cristianismo enfrentó la aversión de los sistemas dominantes: primero, la reacción judaica local, y segundo, la resistencia cultural y religiosa romana, dando lugar a su persecución (Küng 2013: 213). Como defiende Stark (2009: 192), la expansión cristiana de los primeros siglos se cimentó en la predicación, la ejemplaridad santoral y el

\footnotetext{
${ }^{34}$ Cfr. Marcos 16: 15.

35 Véase la relación entre cristianismo y esperanza en Milbank (2010).

36 Sobre la importancia de lo apocalíptico en la teología política, véase Kotsko 2015. Sobre la “cierta calma que conlleva”, véase Žižek y Gunjević 2013.
} 
testimonio del martirologio ${ }^{37}$, alejándose de la contingencia y la beligerancia ${ }^{38}$.

Según Eco (2013), el enemigo, "de no existir, debe crearse" (p. 14). El antagonismo configura un abismo con respecto al Otro, fundamentado en la tensión diferencial entre "mi-nuestro" ethos y el del Otro. Mientras "mi-nuestro ser" es válido, el "ser del Otro" debe ser arrebatado en su corporalidad, su memoria, sus relatos y sus símbolos. Reconvertido en Ello, el Otro es la (de) negación de "mi-nuestro ser", de modo que siendo "yo" humano, el Ello es la némesis de "lo humano", amenazando "lo humano que hay en mí". El Antiguo Testamento contiene numerosas exhortaciones a la erradicación de los noelegidos a manos de los Elegidos ${ }^{39}$, escenas de holocausto que no se limitan a la destrucción simbólica del Otro, sino a la masacre sistemática e incondicional de la identidad contradictoria. La eliminación del Otro, en este caso, procede de un supuesto mandamiento divino, suscrito al transcurso de la "guerra última de la humanidad" (Schmitt 2016: 104). Es, pues, dentro de la narrativa mesiánica que encontramos las categorías Elegidas y no-elegidas, aquellas abyectas y contrarias al orden de Dios que, como tales, pueden ser legítimamente reprimidas.

\section{Conclusión}

Rafael Correa, como personaje político-mediático, asumió y moduló los rasgos característicos de la narrativa mesiánica, hilvanando un juego de identificaciones con la concepción cristológica propia de la teología de la liberación. Dicha estrategia de simulación narrativa no fue necesariamente visible, sino subyacente a los estímulos comunicacionales, propagandísticos y discursivos del régimen, incardinados en la equiparación de la axiología, simbología y relatos del hito mesiánico.

Como pautó la literatura oficialista, en el "Ecuador a.C." las clases subalternas estaban oprimidas por las "élites neoliberales". Este periodo de no-ser-en-plenitud se asemeja, de un lado, a la crisis orgánica conceptualizada por Gramsci, y de otro, al pesimismo previo al clímax del milenarismo. Frente al no-ser civilizatorio del "apocalipsis neoliberal", como hemos observado, el pueblo requería la urgente irrupción de lo salvífico, y es en este contexto donde irrumpió Correa como libertador mesiánico. En contraposición, el "Ecuador d.C." se caracterizó por la promesa soteriológica que, a través de políticas públicas de presunto empoderamiento de los sectores más populares, se constituyó como antesala escatológica de "lo que está por venir", entrelazándose las narrativas correísta y mesiánica, en base al humus cristiano latinoamericano y al ansia de salvación y liberación característica de un pueblo que, como Jesucristo, "es sufriente".

\footnotetext{
${ }^{37}$ Como sienta la declaración Dignitatis Humanae, "la verdad no se impone [...], sino por la fuerza de la misma verdad, que penetra suave y fuertemente en las almas" (Concilio Vaticano II).

${ }^{38}$ Incluso Napoleón se admiró de la pacífica "conquista cristiana” (Soler s/d: 4).

${ }^{39}$ Cfr. Números 21, 31 y 33; Deuteronomio 7 y 31; Josué 1, 6, 7, 8, 9 y 11; Jueces 1; y 1 Samuel 15.
} 


\section{Referencias bibliográficas}

Agamben, G. (2011). Infancia e historia. Buenos Aires: Adriana Hidalgo Editora.

Agamben, G. (2018). Stasis. La guerra civil como paradigma político. Buenos Aires: Adriana Hidalgo Editora.

Agamben, G. (2019). Estado de excepción. Buenos Aires: Adriana Hidalgo Editora.

Aínsa, F. (1990). Necesidad de la utopía. Buenos Aires: Tupac Ediciones.

Beck, U. (2017). La metamorfosis del mundo. Barcelona: Paidós.

Benedicto XVI (2007). "Discurso inaugural de Su Santidad Benedicto XVI".

En Consejo Episcopal Latinoamericano. Documento Conclusivo de la

$V$ Conferencia General del Episcopado Latinoamericano y del Caribe.

Bogotá: Centro de Publicaciones del CELAM.

Berdiáiev, N. (2019). Contra la indignidad de los cristianos. Por un cristianismo de creación y libertad. Salamanca: Ediciones Sígueme.

Campbell, J. (1972). El héroe de las mil caras. Psicoanálisis del mito. México D.F.: Fondo de Cultura Económica.

Cerbino, M., Maluf, M., y Ramos, I. (2016). Los Enlaces Ciudadanos del presidente Rafael Correa. Entre la exaltación del pueblo y el combate a los medios. Quito: FLACSO.

Châtelet, F. (1982). Historia de la filosofía. Vol. IV. Madrid: Espasa-Calpe.

Concilio Vaticano II (1965). Declaración Dignitatis Humanae. Disponible en web: http://www.vatican.va/archive/hist_councils/ii_vatican_council/ documents/vat-ii_decl_19651207_dignitatis-humanae_sp.html.

Consejo Episcopal Latinoamericano (2007). Documento Conclusivo de la $V$ Conferencia General del Episcopado Latinoamericano y del Caribe. Bogotá: Centro de Publicaciones del CELAM.

Correa, R. (2007, 15 de enero). Discurso de toma de posesión como Presidente de la República del Ecuador. Democracia Sur. http://democraciasur. com/2007/01/22/ecuador-discurso-de-toma-de-posesion-de-rafael-correacomo-presidente/

Correa, R. (2012). Ecuador: de Banana Republic a la No-República. Bogotá: Debate.

Cuda, E. (2016). Para leer a Francisco. Teología, ética y política. Madrid: Manantial.

De Domingo, C. (2019). "Dos Ecuadores: antagonismo, conflicto y Gramsci en la mitad del mundo". Colloquia, Academic Journal of Culture and Thought, 6: 35-60. 
De la Torre Espinosa, C. (2015). De Velasco a Correa. Insurrecciones, populismos y elecciones en Ecuador, 1944-2013. Quito: Corporación Editora Nacional.

Desmond, W. (2015). “On Evil and Political Theology”. Political Theology, 16 (2): 93-100. DOI: 10.1179/1462317X14Z.000000000125.

Dickinson, C. (2015). "What Christians need no longer defend: The political stakes of considering antinomianism as central to the practice and history of theology". Crisis \& Critique, 2 (1): 114-150.

Eco, U. (2013). Construir al enemigo. Barcelona: Lumen.

Eco, U., y Martini, C. M. (1997). ¿En qué creen los que no creen? Un diálogo sobre la ética en el fin del milenio. Barcelona: Planeta.

Foa, V. (1997). "Cómo vivo en el mundo, este es mi fundamento". En Eco, U., y Martini, C. M. ¿En qué creen los que no creen? Un diálogo sobre la ética en el fin del milenio. Barcelona: Planeta.

Foucault, M. (1988). "El sujeto y el poder". Revista Mexicana de Sociología, 50 (3): 3-20.

Geertz, C. (2003). La interpretación de las culturas. Barcelona: Gedisa.

Gramsci, A. (1971). El materialismo histórico y la filosofía de Benedetto Croce. Buenos Aires: Nueva Visión.

Gramsci, A. (2001). Cuadernos de la cárcel [Vols. II, IV y V]. México D.F.: Era.

Gramsci, A. (2003). Notas sobre Maquiavelo, sobre política y sobre el Estado Moderno. Buenos Aires: Nueva Visión.

Gramsci, A. (2005). Antología. México D.F.: Siglo XXI.

Gramsci, A. (2009). Las maniobras del Vaticano. Buenos Aires: Godot.

Isler, C. (2008). "El tiempo en las Confesiones de San Agustín”. Revista de Humanidades, 17-18: 187-199.

Jardón, I. (2014). Antonio Gramsci. Una lectura filosófica. Introducción a los Cuadernos de la Cárcel y otros escritos. Barcelona: Yulca.

Kotsko, A. (2015). "The Problem of Evil and the Problem of Legitimacy: On the Roots and Future of Political Theology". Crisis \& Critique, 2 (1): 284299.

Kuffer, P. (2011). Escribir historia significa dar su fisonomía a las cifras de los años. De Benjamin a Sebald a través de la historia: en torno al testimonio y la representación. [Tesis Doctoral]. Adrián, J., y Sàez, B. (dir.). Universitat Autònoma de Barcelona, Barcelona.

Küng, H. (2013). El cristianismo: esencia e historia. Madrid: Trotta.

Labriola, A. (1973). La concepción materialista de la historia. México D.F.: Ediciones El Caballito.

Lacalle, M. (2006). “Tiempo y eternidad en San Agustín”. Revista Comunicación y Hombre, 2: 89-99. 
Laclau, E., y Mouffe, C. (2015). Hegemonía y estrategia socialista. Hacia una radicalización de la democracia. Buenos Aires: Fondo de Cultura Económica.

Lakoff, G. (2016). Politica moral: como piensan progresistas y conservadores. Madrid: Capitán Swing.

Larraín, J. (2008). El concepto de ideología. Vol. 2. El marxismo posterior a Marx: Gramsci y Althusser. Santiago: LOM Ediciones.

López Vigil, M., y López Vigil, J. I. (2007). Un tal Jesús. La Buena Noticia contada al pueblo de América Latina. Disponible en web: https:// radialistas.net/wp-content/uploads/media/uploads/descargas/un_tal_ jesus_-_maria_y_jose_ignacio_lopez_vigil.pdf

López Vigil, M., y López Vigil, J. I. (2008). Otro Dios es posible. 100 entrevistas con Jesucristo en su segunda venida a la Tierra. Disponible en web: https://radialistas.net/wpcontent/uploads/media/uploads/descargas/ otro_dios_es_posible__maria_y_jose_ignacio_lopez_vigil.pdf

López Vigil, M. (2015). "Bienaventurados los ateos porque encontrarán a Dios". Horizonte, 13 (37): 584-591.DOI: 10.5752/P.2175-5841.2015v13n37p584.

Löwy, M. (1999). Guerra de Dioses, religión y política en América Latina. Madrid: Siglo XXI.

Löwy, M. (2015). "Romanticism, Marxism and Religion in the "Principle of Hope" of Ernst Bloch". Crisis \& Critique, 2 (1): 350-355.

Löwy, M. (2019). Cristianismo de liberación. Perspectivas marxistas y ecosocialistas. Barcelona: El Viejo Topo.

Marroquín, I. (2017, 2 de marzo). María López Vigil: Jesús es anarquista y socialista. InformaTVX. https://informatvx.com/maria-lopez-vigil-jesuses-anarquista-y-socialista/

Milbank, J. (2010). "Without Heaven There is Only Hell on Earth: 15 Verdicts on Žižek's Response”. Political Theology, 11 (1): 126-135. DOI: https:// doi.org/10.1558/poth.v11i1.126.

Miralles, A. (2004). "La sangre de los mártires, semilla de cristianos". En Congregación para el Clero de la Santa Sede. El martirio y los nuevos mártires. Ciudad del Vaticano.

Moreno, L. [@Lenin]. (2017, 5 de julio).El diálogo continúa [tweet]. Twitter. https://twitter.com/Lenin/status/882606364710797313.

Nietzsche, F. (2011). Asi habló Zaratustra. Madrid: Alianza.

Nietzsche, F. (2018). La voluntad de poder. Madrid: Editorial EDAF.

Pérez Guartambel, C. (2007). La Asamblea Constituyente. Una oportunidad histórica para el pueblo del Ecuador. Cuenca: Federación de Organizaciones Campesinas del Azuay.

Pérez Ordóñez, P. (2010). "El Presidente Rafael Correa y su política de redención”. Ecuador Debate, 80: 77-94. 
Proaño, L. (1987). Concientización, evangelización, política. Salamanca: Ediciones Sígueme.

Ramos, A. (2008). La ciudad de Dios en Santo Tomás de Aquino. Mar del Plata: Universidad FASTA.

Rancière, J. (2004). "Política, identificación y subjetivación”. Metapolítica, 8 (36): 26-32.

Ratzinger, J. (2011). Jesús de Nazaret. Desde la Entrada en Jerusalén hasta la Resurrección [Vol. II]. Madrid: Encuentro.

Rojas Osorio, C. (1984). "M. Foucault: el discurso del poder y el poder del discurso". Universitas Philosophica, 2 (3): 45-56.

Rousseau, J. J. (2011). El contrato social. Madrid: Biblioteca El Mundo.

Scannone, J. C. (1990). Evangelización, cultura y teología. Buenos Aires: Editorial Guadalupe.

Schmitt, C. (2016). El concepto de lo político. Madrid: Alianza.

Soler, M. (sine data). Napoleón y el cristianismo. Santiago: Progreso.

Spinoza, B. (2014). Tratado Teológico-Político. Madrid: Alianza.

Stark, R. (2009). La expansión del cristianismo. Un estudio sociológico. Madrid: Trotta.

Strauss, L., y Cropsey, J. (comp.). Historia de la filosofia politica. México D.F.: Fondo de Cultura Económica.

TeleSUR. (2006, 23 de diciembre). Rafael Correa dice que misión es recuperar y construir una Patria nueva. Voltairenet.org. https://www.voltairenet.org/ article144445.html.

Vamos Lenín. (2017, 8 de febrero). Lenín perdonó a quienes le dispararon [video]. YouTube. https://www.youtube.com/watch?v=y2Ewp_DHz3w.

Wittgenstein, L. (1988). Investigaciones filosóficas. Madrid: Trotta.

Žižek, S., y Gunjević, B. (2013). El dolor de Dios. Inversiones del Apocalipsis. Madrid: Akal. 